Volume XII, No. 1, pp. 59-69, 2011

\title{
USAGE AND PERCEPTIONS OF INTERNET AD BLOCKERS: AN EXPLORATORY STUDY
}

\author{
J. Christopher Sandvig, Western Washington University, csandvig@wwu.edu \\ Deepinder Bajwa, Western Washington University, deepinder.bajwa@wwu.edu \\ Steven C. Ross, Western Washington University, steve.ross@wwu.edu
}

\begin{abstract}
This exploratory study examines the utilization of ad blocking software by 129 undergraduate business students. It finds that $63 \%$ of the students have tried ad blockers and 62\% are currently using the software on their personal computers. It also found that utilization of ad blocking software is similar for users of both Microsoft Internet Explorer and Mozilla Firefox browsers. The high utilization of ad blocking software has implications for the advertising revenue model that currently supports many web sites and services.
\end{abstract}

Keywords: Internet, Ad blockers, Online advertising, E-commerce.

\section{INTRODUCTION}

Online advertising is the primary source of revenue for many popular web sites. Google, for instance, earned the majority of its $\$ 23.6$ billion in 2009 revenues from advertising [5]. Yahoo also earned most of its 2009 revenue from 131.6 billion banner ads [14]. Most news sites, social networking sites, photo sharing sites, video sites and others are supported by online advertising.

Ad blocking software threatens to undercut the online advertising revenue model. Ad blockers are browser add-ons that allow users to easily block most online advertising. AdBlock Plus, a free add-on for the Firefox browser, is the most downloaded Firefox add-on with over 13 million active daily users [8]. It was listed on PCWorld's list of "100 Best Products of 2007" [4]. A similar extension for Google's Chrome browser, AdThwart, is the second most popular of over 1,200 Chrome extensions [2]. Ad blockers are available for all browsers and many of them are free. Other popular ad blockers include Ad Killer, AdBeGone, KillAd, and AdMuncher.

Ad blockers are extremely easy to employ. One of the authors, who had not previously used an ad blocker, was able to download and install Firefox, and then download and install the AdBlock Plus program, in less than 10 minutes. Although the ad-blocking feature can be turned on and off fairly easily on a per-site basis, completely disabling it requires a browser re-start. One doubts that users will be inclined to perform that operation in the middle of a browsing session.

Ad blockers can also be fine-tuned to permit some content while disallowing most advertisements - but that requires effort and a bit of sophistication on the part of the user. We discuss the "tuning" process at the end of the paper.

Some advertising-supported web sites have attempted to fight ad blockers. When the popular video site Hulu detects ad blockers it posts the message "This program is brought to you by Hulu's advertising partners... you may need to disable your ad blocking software" [16]. The message is displayed for the same amount of time that the commercial would have played. Another popular advertising supported site, Daily Kos, experimented with asking users to disable their ad blockers. It pleaded with users to disable their ad blockers because the site depends upon advertising revenue to cover its operating expenses [11].

Google found itself in on both sides of the ad blocker debate when designing its Chrome browser. The company is supported almost entirely by web advertising but also wanted its browser to include popular features that would make it competitive with other browsers. Google's engineering director, Lunus Upson, said that there were many discussions at Google about allowing ad blockers in its Chrome browser since "Google makes all of its money from advertising.” Ultimately Google decided to allow users to use ad blockers with its Chrome browser [2]. 
Volume XII, No. 1, pp. 59-69, 2011

Advertisers currently have no effective means for circumventing ad blockers. Ad blockers run on the client's browser and are largely outside the control of web sites and advertisers. Browsers are responsible for requesting all the elements of a web page being displayed, including advertising. Typically, advertisements are contained in additional files called by the browser once the main page is received but before it is displayed. Ad blockers examine each request and block requests for advertising content. Ad blocking software identifies advertising content by checking each request against a frequently updated list of advertiser server addresses. The host site for the main web page would not be aware that the third-party pages were not being requested or displayed.

Figure 1 shows the same page, with and without ads displayed. The banner ad in the header area is gone and the entire header is visible. Also, the ad in the right column is gone and the next part of the text moved up.

Figure 1. Effect of AdBlock Plus on a web page

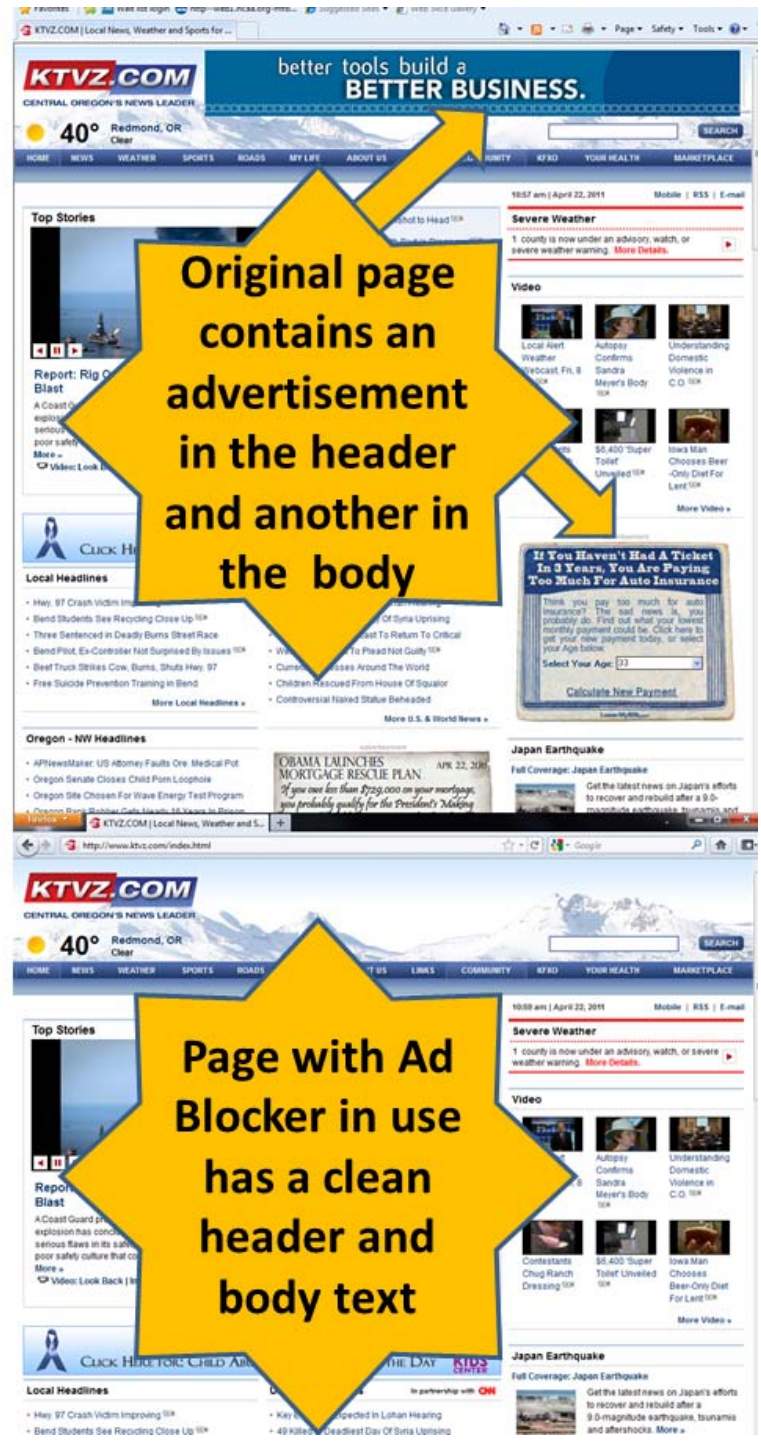

Web site hosts gain income from ads in two ways. In one case, advertisers are charged per display of their ad. In the other case, advertisers are charged per click. In either event, ads that are not visible decrease revenue to the web site host. 
While ad blockers are not currently a significant problem for advertisers, their growing popularity has potential to become an issue if they are adopted by a large number of users. This exploratory study utilizes a sample of websavvy consumers to examine their knowledge, utilization, and perceptions of ad blockers.

\section{LITERATURE REVIEW}

The risks posed to the Internet's revenue model by ad blockers have been recognized by several authors. Pitta [11] observes that if ad blockers became universal "they could eliminate most of the money that supports online services and content." A New York Times article "Whiting out the Ads, but at What Cost" also observes that ad blockers are potentially an "extreme menace to the online-advertising business model" but that for now "the big players have decided to ignore the phenomena" [2].

While considerable research has explored the efficacy of on-line advertising we are not aware of any research that has explored usage and perceptions of ad-blocking software. One reason for the lack of research may be the difficulty of measuring ad blocker utilization. Ad blockers are very difficult for web site owners to detect. Some web sites opposed to ad blockers have resorted to blocking all users of particular browsers as a means of preventing the subset that utilize ad blockers from accessing their sites [6]. Another explanation for the lack of data on ad blocker utilization could be that the two parties most affected by ad blockers, advertising supported web sites and advertisers, do not wish to publicize the products. Doing so could hurt their revenues and further popularize ad blocking software.

The adoption of ad blockers is influenced by user perceptions of advertising. Users with positive perceptions of online advertising have little motivation to use ad blockers. Early research on online advertising found that advertising is liked by approximately one-third of Internet users, disliked by one-third, and the remaining one-third is neutral toward it [13]. Rohrer and Boyd [12] also explored user perceptions of online advertising. The study utilized an "Ad Feedback" link that was deployed across parts of the Yahoo! Network. They found that 1) not all users hate online ads, 2) a minority of users enjoy even the most intrusive ads, 3) users do not like deceptive ads, and 4) users do not like advertisements that usurp user control. Since the survey was conducted via advertising network those individuals who utilized ad blockers were probably underrepresented in the sample.

Online advertising click rates (percentage of ads that users click on) have been found to differ between users of Mozilla's Firefox and Microsoft's Internet Explorer (IE) browsers. A survey conducted across 1,000 European web sites found that users of the Firefox browser clicked on web advertisements only $22 \%$ as frequently as users of IE. During a two month period only 0.11 percent of Firefox users clicked on an ad, versus 0.5 percent of IE users. The authors of the study attributed the differences to the different surfing habits of Firefox and IE users plus Firefox's integrated pop-up ad blocker [7].

This purpose of this study is to extend current knowledge of ad blocker utilization and user perceptions of ad blocking software. In the following sections of this paper we describe the study's methodology, results, and discuss the implications of the findings for practitioners and researchers.

\section{RESEARCH METHODOLOGY}

Our study utilizes a group of web-savvy college students to explore the following questions:

1. Awareness of ad-blocking software

2. Experience with ad blockers

3. Utilization of ad blockers

4. Relationship between browser choice and ad blocker utilization

5. Perceived advantages and disadvantages of using ad blockers

To explore these questions we surveyed 129 undergraduate business students at a Pacific Northwest University. Subjects received extra credit in a Management Information Systems (MIS) course for participating in the study. All students who were eligible to participate did so, providing a 100\% response rate. A web-based survey was used 
to collect demographic data (age, gender, Internet access, devices used to access the Internet, browser used, expertise level for finding information on the Internet, and average time spend daily using the Internet (minutes per day). A 5-point scale ( 1 = poor, 2 = below average, 3 = average, $4=$ above average, $5=$ expert $)$ was used to measure the expertise level of the respondents. To capture detailed use statistics, we also collected data on the amount of time our respondents spent every day on the Internet for popular activities like: completing class assignments, blogging, reading newspapers, visiting humor sites, web surfing, visiting employment sites, Facebook use, watching TV shows, accessing YouTube, gaming, and using Wikipedia. A seven-point scale identifying time intervals was used for each of the activities $(1=$ less than half hour, 2 = between half hour to less than 1,3 = between 1 to less than 1.5 hours, 4 = between 1.5 hours to less than 2 hours, 5 = between 2 hours and less than 2.5 hours, $6=$ between 2.5 hours and less than 3 hours, $7=3$ or more hours In addition, the respondents were asked to indicate their awareness of ad blockers, past and current use of ad blockers, and qualitative assessments of the advantages and disadvantages of ad blockers. The participants completed the survey over a six day period in a computer lab at the college campus.

\section{ANALYSES AND RESULTS}

Table 1 shows the respondent profile. The demographics of the sample are skewed toward youth (average age 21.5 years) and above average educational attainment. The sample represents a population that will most likely be heavy Internet users for many years and a demographic group that is highly desirable to advertisers.

All of the respondents owned personal computers, compared to an average of $80.6 \%$ for U.S. households. Seventy percent owned smart-phones, which is more than twice the $31 \%$ market penetration of all U.S consumers [10]. Ninety-nine percent had Internet access at home compared to an average of $92 \%$ for US households [9]. All of the students rated themselves average or above for expertise for finding information on the Internet. This high perception of computer efficacy is consistent with previous research that found business students possess a significantly higher degree of computer self-efficacy than students from other disciplines [1].

\section{Table 1. Demographics of Study Participants}

\begin{tabular}{|c|c|}
\hline Gender & $\begin{array}{l}\text { Male: } 74(57 \%) \\
\text { Female: } 55(43 \%)\end{array}$ \\
\hline Age & Average: 21.5 years \\
\hline $\begin{array}{l}\text { Own personal comput- } \\
\text { er: }\end{array}$ & $\begin{array}{l}\text { Yes: } 128(100 \%) \\
\text { No: } 0(0 \%)\end{array}$ \\
\hline $\begin{array}{l}\text { Own phone capable of } \\
\text { conducting Internet } \\
\text { search }\end{array}$ & $\begin{array}{l}\text { Yes: } 89(70 \%) \\
\text { No: } 39(30 \%)\end{array}$ \\
\hline $\begin{array}{l}\text { Have Internet access at } \\
\text { home: }\end{array}$ & $\begin{array}{l}\text { Yes: } 126(99.2 \%) \\
\text { No: } 1(0.8 \%)\end{array}$ \\
\hline $\begin{array}{l}\text { Wireless Internet at } \\
\text { home: }\end{array}$ & $\begin{array}{l}\text { Yes: } 114(90 \%) \\
\text { No: } 12(10 \%)\end{array}$ \\
\hline $\begin{array}{l}\text { Average experience } \\
\text { using the Internet }\end{array}$ & 11.3 years \\
\hline $\begin{array}{l}\text { Browser typically } \\
\text { used: }\end{array}$ & $\begin{array}{l}\text { Internet Explorer: } 42 \text { (33\%) } \\
\text { Firefox: } 58(45 \%) \\
\text { Chrome } 12(9 \%) \\
\text { Safari (Mac): } 16(12 \%)\end{array}$ \\
\hline $\begin{array}{l}\text { Expertise at finding } \\
\text { information on Inter- } \\
\text { net: }\end{array}$ & $\begin{array}{l}\text { Poor: } 0 \\
\text { Below average: } 0 \\
\text { Average: } 41(32 \%) \\
\text { Above average: }(68(53 \%) \\
\text { Expert: } 20(15 \%)\end{array}$ \\
\hline $\begin{array}{l}\text { Average minutes } \\
\text { spend daily on Inter- } \\
\text { net: }\end{array}$ & 119 minutes \\
\hline
\end{tabular}


Volume XII, No. 1, pp. 59-69, 2011

\section{Quantitative Assessments}

Study participants differed from the general population of Internet users in other important ways. Firefox was the preferred browser for $45 \%$ of the participants, versus $22 \%$ for all Internet users, while Internet Explorer was used by $33 \%$ of participants, versus 57\% for all Internet users [15]. The average reported Internet usage by study participants was 119 minutes per day.

Overall, we found that the study participants had a high awareness and usage of ad-blocking software. Over threequarters (79\%) of the study participants had heard of ad blocker browser add-ons, $63 \%$ had tried using ad blockers and $62 \%$ were currently using ad blockers on their personal computers.

First, we explored the utilization of ad blockers by gender, and browser preference. A slightly higher percentage of males than females, $66 \%$ and $57 \%$ respectively, use ad blockers on their personal computer. The percentage of IE and Firefox users using ad blockers was almost even, at 59\% and 61\% respectively. Safari users were the heaviest users of ad blockers, at $80 \%$, while Chrome users were the lightest users, at $50 \%$ utilization. However the number of Safari and Chrome users in the sample was small, 15 and 10 individuals respectively, so these figures must be interpreted with caution. Results are summarized in Table 2.

Table 2. Utilization of browser and ad blockers

\begin{tabular}{|l|l|l|l|}
\hline Browser & $\begin{array}{l}\text { Use ad } \\
\text { blockers }\end{array}$ & $\begin{array}{l}\text { Do not use } \\
\text { ad blockers }\end{array}$ & Total \\
\hline IE & $59 \%(19)$ & $41 \%(13)$ & $30 \%(32)$ \\
\hline Firefox & $61 \%(31)$ & $39 \%(20)$ & $47 \%(51)$ \\
\hline Chrome & $50 \%(5)$ & $50 \%(5)$ & $9 \%(10)$ \\
\hline Safari & $80 \%(12)$ & $20 \%(3)$ & $14 \%(15)$ \\
\hline Total & $62 \%(67)$ & $39 \%(41)$ & $100 \%(108)$ \\
\hline
\end{tabular}

Second, we focused on the use of ad blockers for the various Internet activities. Interestingly, the study respondents spent the most amount of time every day on the Internet for completing school assignments, networking on Facebook, and web surfing. They spent the least amount of time every day on the Internet visiting employment sites. We conducted t-tests to explore any significant differences in time spend on Internet for various activities between the two groups of respondents (i.e. those that currently used ad blockers and those that didn't use ad blockers). No significant results were detected. The results are shown in Table 3.

Figure 2 shows the stacked responses from those that use ad blockers and those that don't use ad blockers for all the Internet activities. The findings suggest that the larger majority of our respondents that use the Internet for various activities use ad blockers. 
Volume XII, No. 1, pp. 59-69, 2011

Table 3. Internet activities and ad blocker use

\begin{tabular}{|lrrrl|}
\hline \multicolumn{4}{c}{ Ad-Blocker Use } \\
Internet Use & \multicolumn{1}{c|}{ Yes } & \multicolumn{1}{c|}{ No } \\
& Mean & \multicolumn{1}{c}{ SD } & Mean & \multicolumn{1}{l|}{ SD } \\
Assignments & 4.82 & 1.33 & 5.05 & 1.32 \\
Blogging & 2.17 & 1.44 & 2.32 & 1.51 \\
Employment Sites & 1.93 & 1.13 & 1.63 & 1.02 \\
Facebook & 4.49 & 1.78 & 4.66 & 1.54 \\
Gaming & 2.31 & 2 & 2 & 1.84 \\
Humor Sites & 2.57 & 1.33 & 2.44 & 1.52 \\
Newspaper & 2.44 & 1.31 & 2.44 & 1.38 \\
TV & 3.54 & 2.14 & 3.27 & 2.07 \\
Web Surfing & 4.15 & 1.77 & 3.97 & 1.39 \\
Wikipedia & 2.63 & 1.3 & 2.71 & 1.08 \\
YouTube & 3.33 & 1.73 & 3.29 & 1.66 \\
\hline
\end{tabular}

Figure 2. Overall ad blocker use behavior

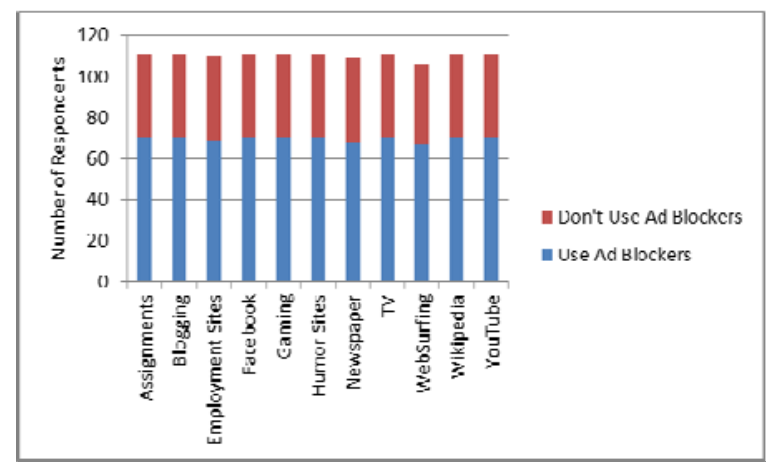

Our next quantitative assessments focused on expertise level and ad blocker use behavior. In order to explore relationships between ad blocker use behavior and the expertise level of our respondents, we conducted t-tests to detect any differences in expertise level between the two ad blocker use groups (those that currently used ad blockers and those that don't use ad blockers). Once again, no significant results were detected in expertise level between the two groups. The mean expertise level, however, was higher for the group that used ad blockers (3.92) than the group that did not use ad blockers (3.80).

To further explore the relationship, we formed three groups for self-perception of search expertise level. Since none of the respondents indicated that their expertise was poor or below average, the three groups included responses from respondents with average expertise (low), above average expertise (medium), and experts (high). Figure 3 shows the trends of ad blocker use behavior for the three expertise level groups. The findings indicate an increasing linear trend for respondents that had tried ad blockers in the past. The trend for respondents that currently used ad blockers had a linear increase between medium and high expertise level respondents. The overall trends indicate that a large percentage of respondents with high expertise level have tried ad blockers in the past and also currently use ad blockers. The findings should be interpreted with caution as they indicate general trends and not statistically significant results. 
Volume XII, No. 1, pp. 59-69, 2011

Figure 3. Expertise level and ad blocker use

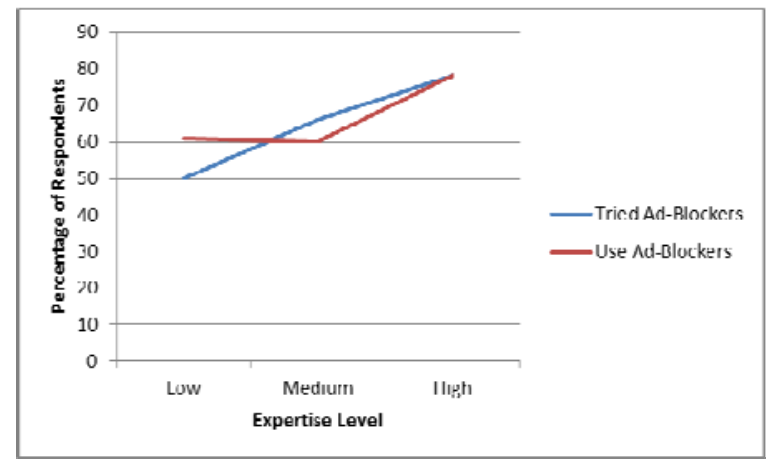

To gain insights into expertise level of respondents, we conducted a one way analysis of variance (ANOVA) to detect for differences in Internet use for various activities between the three expert level groups. Significant results were detected for all the Internet activities accept for Facebook use and completing class assignments. In general, respondents with high expertise spent more time on the Internet for the majority of the activities than those with low level of expertise.

\section{Qualitative Assessments}

Study participants were asked the following two open-ended questions: "What do you see as the advantages of ad blockers?" and "What do you see as the disadvantages of ad blockers?" Tables 4 and 5 summarize the most frequent responses (responses have been rephrased by the authors to capture the intent of each response). Questions were open ended so respondents could list more than one advantage or disadvantage. Features mentioned less than three times are not included.

A word count was utilized to identify frequently utilized words. When describing advantages of ad blockers the words "annoying" and "distracting" were each used 21 times to describe on-line ads. The words "pop," "popup" and "popover" were used a total of 31 times, while "virus" was used seven times and "spam" six times.

Table 4. Advantages of Ad-blocking software

\begin{tabular}{|l|l|}
\hline Frequency & Advantage \\
\hline 50 & Eliminate annoying ads \\
\hline 32 & Fewer distractions and disruptions \\
\hline 10 & Reduce risk of viruses \\
\hline 10 & Reduce screen clutter \\
\hline 9 & Prevent ads from slowing computer \\
\hline 4 & No popup-ads \\
\hline 3 & Do not know what ad blockers do \\
\hline
\end{tabular}


Volume XII, No. 1, pp. 59-69, 2011

Table 5. Disadvantages of Ad-blocking software

\begin{tabular}{|l|l|}
\hline Frequency & Disadvantage \\
\hline 39 & $\begin{array}{l}\text { Could block ads that are useful, } \\
\text { relevant or could save money. }\end{array}$ \\
\hline 22 & $\begin{array}{l}\text { Can block popups needed to use } \\
\text { website. }\end{array}$ \\
\hline 12 & No disadvantage \\
\hline 8 & $\begin{array}{l}\text { Websites do not receive advertising } \\
\text { revenue }\end{array}$ \\
\hline 5 & $\begin{array}{l}\text { Ad-blocking software can slow } \\
\text { down computer }\end{array}$ \\
\hline 4 & $\begin{array}{l}\text { Can block non-advertising page } \\
\text { content }\end{array}$ \\
\hline 3 & Do not know what ad blockers do \\
\hline
\end{tabular}

The primary disadvantage of ad blockers cited by study participants was that they could potentially not see an advertisement that was interesting, relevant, or could save them money. A tally of individual words did not find any frequently used words to describe disadvantages.

\section{DISCUSSION}

A surprising $62 \%$ of the study participants utilize ad blockers on their personal computers. Of the $63 \%$ of study participates who had tried ad blocking software almost are currently using the software. These finding should be of concern to on-line advertisers as well as web sites that rely heavily upon advertising for their revenues.

The study participants differed from the general population of Internet users in several dimensions. Compared to the overall population of Internet users, they were younger, more likely to own a personal computer, more than twice as likely to own a smart phone, and more than twice as likely to use the Firefox browser. The high number of Firefox users in the sample can be partially attributed to the sample demographics. A survey by Comscore.com found that compared to IE users Firefox users are more likely to be young, educated or seeking education, have broadband connections, and are affluent. They are also more likely to visit online software sites, blogs, books sites, educational sites and to read technology news [3]

Another surprise was the almost equal utilization of ad blockers by users of Firefox and IE, $61 \%$ and 59\% respectively. Firefox provided one of the first effective and free ad blockers and the browser tends to be associated with the software [6]. One explanation for this finding may be that effective and easy-to-use ad blockers are now available for all browsers, including IE.

We did not find any significant differences between overall Internet use between respondent groups that currently used ad blockers and those that did not use ad blockers. Similarly, we did not observe any significant differences between the expertise level of the respondents and their ad blocker use behavior. However, interestingly enough, our trends did indicate a linear increase in ad blocker use behavior as the level of expertise increased from low to high. We also found that respondents with higher level of expertise tend to spend significantly more time on the Internet for various activities than respondents that have lower levels of expertise. The above insights suggest that the use of ad blockers will likely increase as the population of Internet users becomes savvy and acquire higher levels of expertise. Since these expert users also spend significantly more time on Internet activities, use of ad blockers could influence revenues from advertisements in the future.

Qualitative perceptions of ad blockers also exposed some advantages and disadvantages. The most frequently mentioned advantage of ad blockers was that they "eliminate annoying ads". This was mentioned by 50 of our respondents ( $41 \%$ of participants). The second most frequently mentioned advantage, "fewer distractions and disruptions," 
expresses a similar perception of online advertising. The words "annoying" and "distracting” were frequently used to describe online advertising.

On the other hand, some study participants did perceive that online advertising can be useful. The most frequently mentioned disadvantage of ad blocking software was that it "could block ads that are useful, relevant or could save me money." This finding is consistent with those of Rohrer and Boyd [12] who found that not all users hate online advertising.

Only eight study participants (7\%) mentioned the lack of ad revenue to web sites as a disadvantage of ad blockers. This lack of concern for the financial impact of ad blockers on advertising supported web sites could be a future concern to advertisers.

The findings of this study suggest that ad blockers could become a significant problem for advertisers and advertising supported websites. Many study participants expressed a negative view of online advertising, the majority (62\%) utilize ad blocking software on their personal computers, and only a handful (7\%) mentioned that ad blockers deprive advertising supported web sites of revenue.

\section{CONCLUSIONS AND LIMITATIONS}

This exploratory study has implications for both practitioners and for future research. It also has some limitations that should be acknowledged.

This study suggests that ad blocking software could become a significant problem for advertisers and advertising supported web sites. This could be especially critical as the population of Internet users becomes more knowledgeable.

The results of this exploratory research suggest several avenues for future research related to ad blocking software. Researchers could study the ad blocker issue from two perspectives

- understanding what users do and why

- investigate the measures that web site owners can take to discourage ad blocker usage

This research is a start toward the first issue: understanding user behavior.

One important question would be whether those most likely to buy goods and services on the Internet are the ones most likely to employ ad blockers. It might be that those prone to use ad blockers are not prone to respond to (click on) display ads in any event. Therefore no real market share is being lost. More investigation of both ad blocker usage and Internet buyer behavior is needed to determine the relationship between ad blocker users and buyer behavior

Researchers should delve more deeply into the factors that influence the adoption of ad blocking software. This knowledge could help advertisers design their products to minimize future adoption of ad blockers. It would also be interesting to explore how users of ad blocking software became aware of the products and how long they have been utilizing them. Another avenue would be to explore user's attitudes about online advertising to gain a better understanding of how ad blockers fit into this larger picture. Finally, it would be interesting to further investigate why individuals who have tried ad blockers don't currently use them. This could provide insights into how to convert non-adopters into adopters or vice-a-versa.

One countermeasure that advertisers and advertising web sites could undertake to minimize the adoption of ad blocking software is to make online advertising less annoying and more relevant to users. If users see some value in online advertisements, or at least do not find them too annoying, they will be much less likely to employ ad blocking software.

One problem that online advertisers face is that a few "bad players" can impact the entire industry. The majority of advertisers could adopt "user friendly" advertising policies, but a minority may find that their advertising effective- 
ness is enhanced by high-impact advertisements that are annoying to users. If users react to these high impact ads by adopting ad blocking software it can affect even the good players. The default setting on many ad blockers is to block all advertising, not just high impact ads. While users often have the option of fine-tuning the ad blockers, many will not make the effort.

Researchers should investigate whether persons routinely turn ad blockers on and off, either completely or for specific sites. AdBlock Plus offers a way to alter its behavior on a per-site basis. How well known is this feature? We investigated the ease with which AdBlock Plus software can be tuned. In the lower-left corner of the Firefox screen is an octagonal ("stop sign") icon containing the letters "ABP." Clicking it allows one to see what is blocked and to "Open blockable items." Clicking on one of the items blocked opened the window illustrated in Figure 4. Employing an exception filter, we were able to remove the block on the Weather Underground site.

Due to browser security considerations it is unlikely that web sites could directly affect a browser setting (i.e., turn off the blocker). Therefore, web sites must employ methods to alter user behavior. The problem is not unlike that faced by e-mailers who must attempt to circumvent spam filters.

One strategy that websites could employ would be to display a message "behind" where an ad would appear. If the ad does not appear, the message does - the message could tell the visitor what is being missed (e.g., "Great Deals on Music") and point the visitor to instructions on how to turn off the ad blocker for their site.

One limitation of this study is the narrow demographic of the convenience sample. While undergraduate students are an important demographic to advertisers they are not representative of the population of Internet users. This factor limits the generalizability of this study. Future studies should expand the sample to include more diversity in age, educational attainment, and income levels.

\section{Figure 4. Changing the filter rule to allow a specific web address}

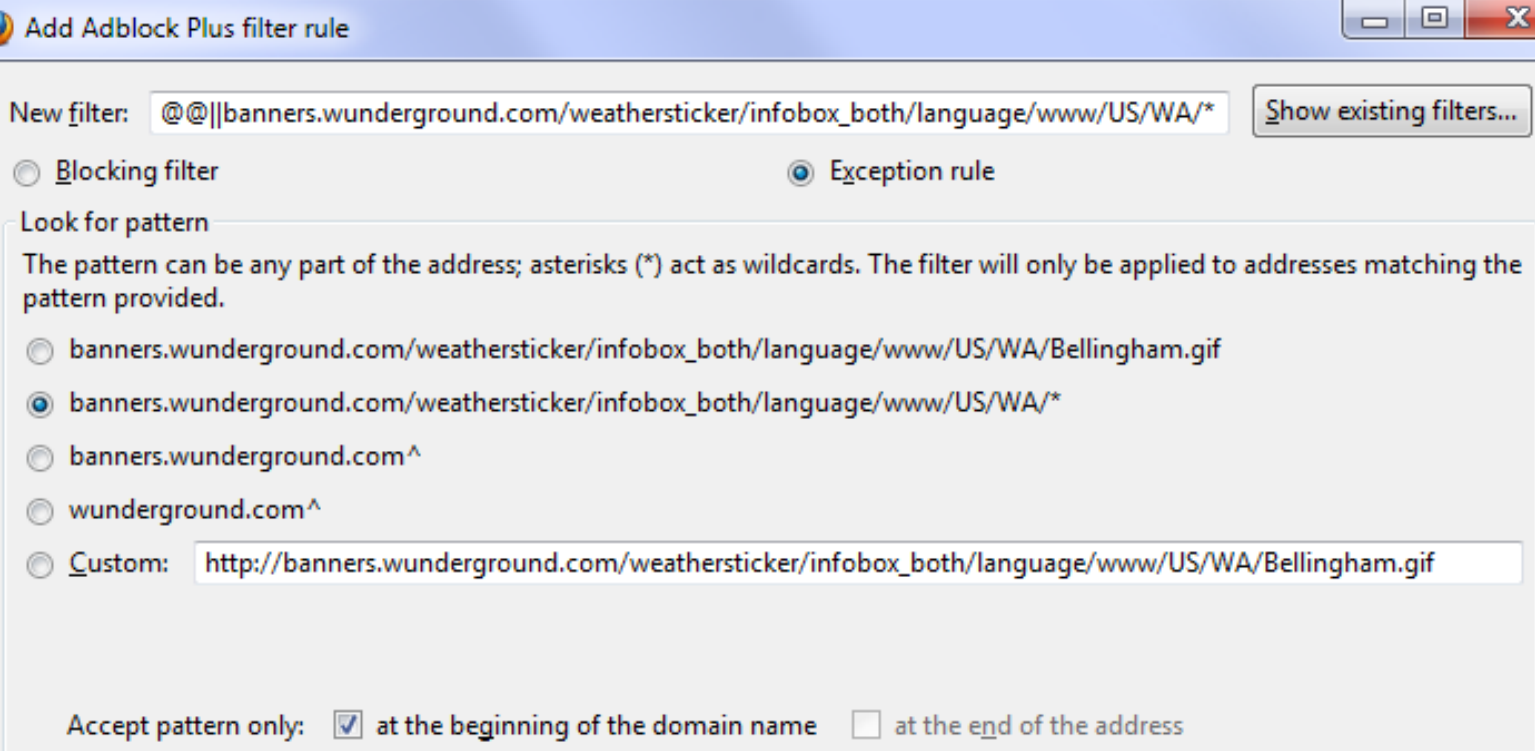




\section{Issues in Information Systems}

Volume XII, No. 1, pp. 59-69, 2011

\section{REFERENCES}

1. Chung, S., P. Schwager, and D. Turner (2002) “An Empirical Study of Students' Computer Self-Efficacy: Differences among Four Academic Disciplines at a Large University,” Journal of Computer Information Systems, (42:4) 1-7.

2. Cohen, N (2010) “In Allowing Ad Blockers, a Test for Google,” Jan. 3. Retrieved May 22011 from http://www.nytimes.com /2010/01/04/business/media/04link.html

3. comScore.com (2007) “Firefox vs. Internet Explorer,” April 10. Retrieved May 2, 2011 from http://blog.comscore.com/2007/04/

4. Dahl, E. (2007) “The 100 Best Products of 2007,” May 21. Retrieved May 2, 2011 from http://www.pcworld.com/article/131935-11/the_100_best_products_of_2007.html

5. Edwards, J. (2010) “Google’s Revenue Breakdown Shows It Controls Even More Advertising Than You'd Think,” May 25. Retrieved May 1, 2011 from http://www.bnet.com/blog/advertising-business/google-8217srevenue-breakdown-shows-it-controls-even-more-advertising-than-you-8217d-think/4932

6. Kirk, J (2007) “Firefox ad blocker extension causes angst,” August 23. Retrieved May 2,1011 from http://www.infoworld.com /t/applications/firefox-ad blocker-extension-causes-angst-900 http://www.infoworld.com/t/applications/firefoxad blocker-extension-causes-angst-900

7. Mason, I. (2004) “Firefox users ignore online ads, report says,” Dec. 6. Retrieved May 2, 2011 from http://news.cnet.com /Firefox-users-ignore-online-ads,-report-says/2100-1024_3-5479800.html

8. Mozilla.org (2011) AdBlock Plus Statistics, Retrieved April 27, 2011 from https://addons.mozilla.org/enUS/firefox/statistics/addon/1865

9. Nielsen.com (2008) “An Overview of Home Internet Access in the U.S.,” December. Retrieved February 2, 2011 from http://blog.nielsen.com/nielsenwire/wp-content/uploads/2009/03/overview-of-home-Internet-accessin-the-us-jan-6.pdf

10. Perez, S. (2011) “Apple Still U.S. Smartphone Market Share Leader...Barely,” Jan. 3. Retrieved May 2, 2011 from http://www.readwriteweb.com/archives/apple_still_us_market_share_leader_in_smartphones.php

11. Pitta, D. (2008) “The world wide web faces a life and death challenge: pop-up ad blockers," Journal of Consumer Marketing, 25(7).

12. Rohrer, C., J. Boyd (2004) "The rise of intrusive online advertising and the response of user experience research at Yahoo!," Proceeding CHI EA '04 CHI '04 extended abstracts on Human factors in computing systems, (CHI EA '04). ACM, 1085-1086.

13. Schlosser, A, S. Shavitt, and A. Kanfer (1999) "Survey of Internet users' attitudes toward Internet advertising,” Journal of Interactive Marketing, 13(3), 34-54.

14. Vascellaro, J. (2011) “Facebook Makes Gains in Web Ads,” May 12. Retrieved May 2, 2011 from http://online.wsj.com/article /SB10001424052748704250104575238661210740510.html

15. Vaughan-Nichols, S. (2011) , "Internet Explorer gains Web browser market share from Firefox,” March 2. Retrieved May 2, 2011 from http://www.zdnet.com /blog/networking/Internet-explorer-gains-web-browser-market-share-from-firefox/743

16. Whoriskey, P. (2008) “One Man, One Long List, No More Web Ads,” June 25. Retrieved May 2, 2011 from http://www.washingtonpost.com/wp-dyn/content/article/2008/06/24/AR2008062401287.html 